\title{
Dynamics of Cryphonectria hypovirus Infection in Chestnut Blight Cankers
}

\author{
Sarah Franziska Bryner, Simone Prospero, and Daniel Rigling
}

WSL Swiss Federal Research Institute, CH-8903 Birmensdorf, Switzerland.

Accepted for publication 24 February 2014.

\begin{abstract}
Bryner, S. F., Prospero, S., and Rigling, D. 2014. Dynamics of Cryphonectria hypovirus infection in chestnut blight cankers. Phytopathology 104:918-925.

Virulent strains of the chestnut blight fungus Cryphonectria parasitica cause lethal bark cankers on chestnut trees. Infection of $C$. parasitica with Cryphonectria hypovirus 1 in Europe biologically controls this disease, leading to nonlethal and inactive cankers. Unexpectedly, virusfree $C$. parasitica strains have been isolated from inactive cankers. In this study, we compared the virulence of virus-infected and virus-free $C$. parasitica strains isolated from either inactive or active cankers on chest-

and immigration of foreign vegetative compatibility (vc) types over a period of 13 years in a coppice forest. Overall, the virulence of virus-free C. parasitica strains isolated from inactive versus active cankers did not differ. Significant differences were only attributed to virus infection. Virus infection and fungal strain composition in cankers changed over time. Foreign vc types immigrated into cankers and virus-free cankers became virus-infected within a few years. Most of the cankers were callused over time and became inactive. However, we observed that the virus did not always persist in these cankers. This study demonstrates that virus spread occurs effectively in European chestnut forests and that this biocontrol system is highly dynamic.
\end{abstract} nut seedlings and sprouts. In the seedling experiment, we assessed canker growth and seedling mortality. In the sprout experiment, we also assessed canker growth and made fungal reisolations to determine virus infection
Additional keywords: Castanea sativa.
Chestnut blight is a serious tree disease in forests and orchards. Responsible for this disease is the ascomycete fungus Cryphonectria parasitica $(3,24)$. The pathogen infects the bark and cambium of the tree through wounds and causes lethal bark cankers on susceptible chestnut (Castanea spp.). Active cankers usually enlarge rapidly and assume a sunken appearance due to the death of the cambium under the infected bark. The cankers may girdle the branch or stem and induce death to all plant parts distal to the infection, eventually killing the entire tree $(24,26)$. C. parasitica is native to East Asia, where chestnut blight is only a minor problem because the local chestnut species (primarily Castanea mollissima and $C$. crenata) are resistant to the disease (19).

Cryphonectria parasitica was accidentally introduced to North America in $\approx 1900$ and to Europe in $\approx 1930(12,14)$. The American and European chestnut (Castanea dentata and $C$. sativa, respectively) had not coevolved with $C$. parasitica and, thus, were highly susceptible (1). After introduction, C. parasitica spread rapidly throughout the local chestnut populations. In a devastating epidemic, the disease destroyed the native chestnut forests in North America by killing most of the mature American chestnut trees (2).

In Europe, the epidemic took a similar course in the beginning. Surveys in natural populations of European chestnut revealed a general susceptibility to the disease, with little variation among trees (4). Nevertheless, a few years after introduction, superficial, sometimes callusing, cankers were observed that eventually stopped expansion and became inactive (14). These inactive

Corresponding author: D. Rigling; E-mail address: daniel.rigling @wsl.ch

* The $e$-Xtra logo stands for "electronic extra" and indicates that Figures 1 and 2 apppear in color online.

http://dx.doi.org/10.1094/PHYTO-03-13-0069-R

(c) 2014 The American Phytopathological Society cankers assumed a dark appearance with quiescent margins and were colloquially designated as "healed" cankers. Responsible for the recovery of the cankers was an infection of $C$. parasitica with Cryphonectria hypovirus 1 (CHV-1). CHV-1 is an unencapsidated RNA virus of the genus Hypovirus $(9,16)$. The hypovirus (hereafter referred to simply as "virus") does not kill $C$. parasitica but it reduces the pathogenic potential of the fungus, a phenomenon called hypovirulence (29). It further inhibits sexual reproduction, strongly attenuates growth and asexual sporulation, and reduces pigmentation of $C$. parasitica (19).

CHV-1 was presumably introduced together with its host, $C$. parasitica, to Europe and spread naturally throughout the $C$. parasitica populations by transmission from one fungal individual to another (7). In European regions where natural hypovirulence did not appear, the rapid dissemination of CHV-1 was further aided by active biocontrol efforts (15). To date, chestnut blight incidence in Europe is high but, due to hypovirulence, the disease is maintained at low severity in most regions $(6,19,27)$.

The Cryphonectria-hypovirus pathosystem is a famous textbook example for a successful biocontrol system using mycoviruses $(1,20)$. Prevalence of $\mathrm{CHV}-1$ and induced hypovirulence in $C$. parasitica has most likely prevented a devastating chestnut blight epidemic and the destruction of the European chestnut forests to date. Therefore, in this study, we wanted to investigate the dynamics of this biocontrol system. As described above, inactive cankers are generally associated with virus infection. However, C. parasitica isolations revealed that not only virusinfected but also virus-free $C$. parasitica strains are frequently recovered from inactive cankers $(5,8,23)$. This is unexpected and raises the question of whether inactive cankers can also be the result of virus-free $C$. parasitica strains with naturally low virulence. To address this question, we tested and compared the virulence of virus-free $C$. parasitica strains isolated from inactive cankers and the virulence of virus-free $C$. parasitica strains isolated from active cankers. An alternative hypothesis explaining 
the observation of virus-free $C$. parasitica strains in inactive cankers would be the lack of persistence of CHV-1 in these cankers over time. To explore the potential of this hypothesis, we assessed the presence of the virus in cankers over time by repeated $C$. parasitica isolations from the same cankers. Furthermore, we assessed the vegetative compatibility (vc) types of these $C$. parasitica isolates. $C$. parasitica vc types are determined by at least six bi-allelic genetic loci (10), which enabled us to detect potential immigrations of new fungal strains into the cankers.

\section{MATERIALS AND METHODS}

C. parasitica strains. In this study, both virus-free and virusinfected $C$. parasitica strains were used. All strains were isolated in 1994 from either active or inactive chestnut blight cankers (Fig. 1; Table 1) in two naturally infected chestnut coppice forests in Ticino, Switzerland. Active cankers exhibit a red, actively growing border and are rapidly expanding. In contrast, inactive cankers are characterized by a dry, black surface and quiescent margins.

Seedling inoculation experiment. For this experiment, five different $C$. parasitica strains of each of four types were used: $\mathrm{O}$-active, O-inactive, $\mathrm{W}$-active, and $\mathrm{W}$-inactive (Table 1). In addition, one virus-free (O-control) and one virus-infected (W-control) strain from our culture collection at WSL were used as controls. Each strain was grown on potato dextrose agar (PDA) Difco, Voight Global Distribution, Lawrence, MD) at $25^{\circ} \mathrm{C}$ in the dark for 5 days and then inoculated onto five 4-year-old chestnut seedlings. The seedlings were offspring of the same mother tree grown in a nursery. One circular wound was made with a cork borer ( $5 \mathrm{~mm}$ in diameter) into the stem of each seedling and filled with two mycelia mats of the same strain obtained from the growing edge of the PDA culture. The wounds were then covered with transparent adhesive tape to prevent desiccation. For the duration of the experiment, all infected seedlings were kept in a nursery plot outdoors in Bellinzona (Ticino), southern Switzerland. All seedling inoculations were performed on 26 June 1995. Canker area and seedling mortality were used as measures for virulence of the strains. The canker area on each seedling was assessed 2 months (August 1995), 6 months (December 1995), and 13 months (July 1996) after inoculation by measuring two diameters of each lesion, one along the longitudinal and a second along the lateral axis of the stem. Because the inoculations killed a large proportion of seedlings during summer 1996, no further canker measurements were used for the analysis thereafter. We assessed the mortality of seedlings by recording the number of seedlings that had died by 27 September 1996.

Sprout inoculation experiment. In this experiment, three different $C$. parasitica strains of type $\mathrm{O}$-active and three strains of type $\mathrm{O}$-inactive were used. One virus-free $(\mathrm{O}$-control) and one virus-infected (W-control) strain were used as controls. Inoculations of sprouts were performed as described for the seedling inoculation experiment. Five chestnut sprout clusters composed of at least eight individual sprouts were inoculated with each $C$. parasitica strain. Sprouts of the same cluster were growing from a single stump and were clones of the same tree. In the experiment, each sprout cluster was equivalent to one of five blocks and one replicate of each $C$. parasitica strain was used for one inoculation within each block. The sprouts were 11 years old and situated in a coppice forest in Lumino (Ticino), southern
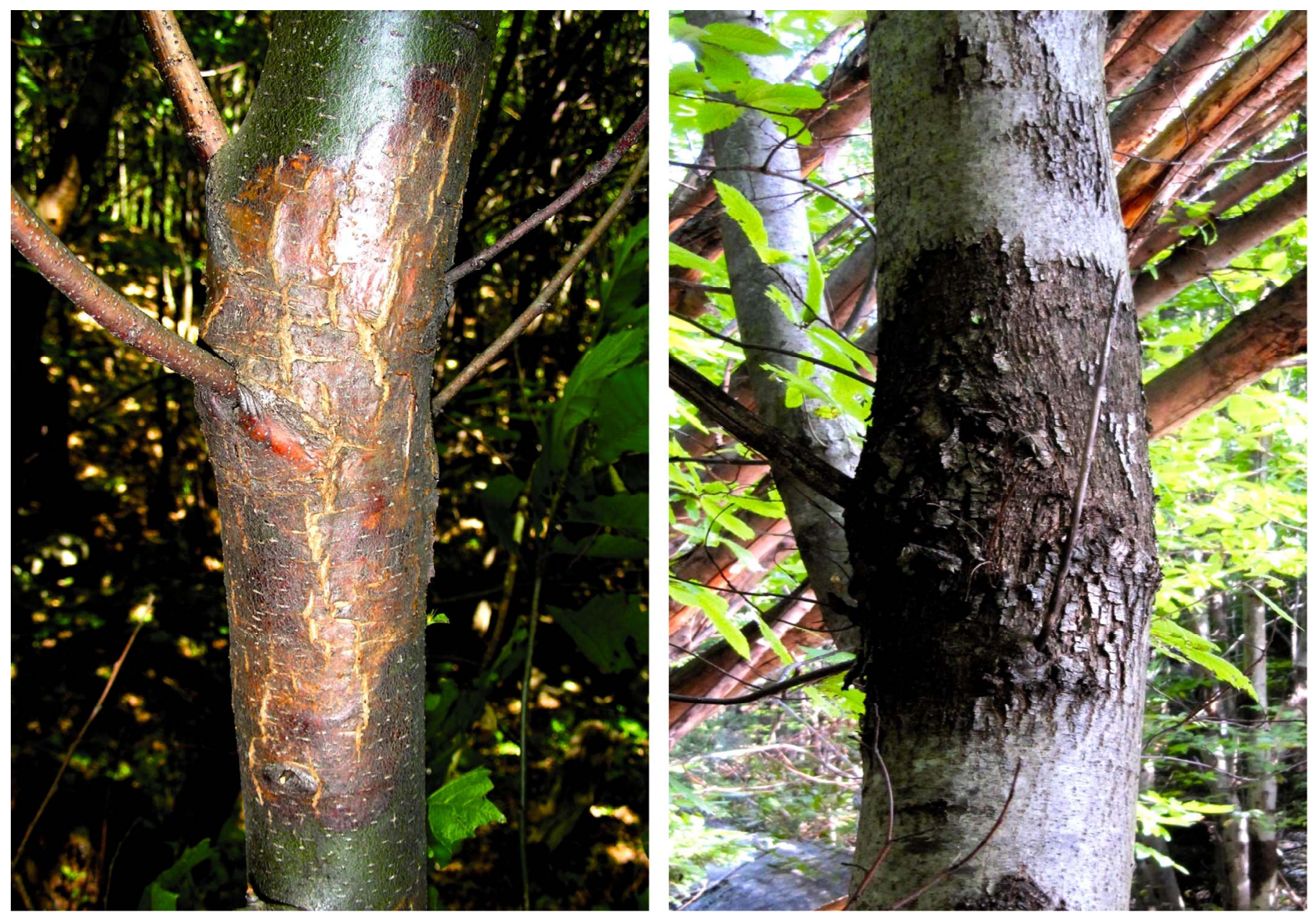

Fig. 1. Active (left) and superficial, inactive (right) chestnut blight cankers. 
Switzerland, where natural hypovirulence is present (5). Inoculations were performed on 26 June 1995. The canker areas produced by the strains were measured 6 months (November 1995), 15 months (September 1996), 30 months (November 1998), and 39 months (September 1998) after inoculation, as described above.

In addition, we visually assessed the morphological development of all cankers at five time points: March and November 1997, September 1998, November 1999, September 2000, August 2004, and September 2008. We distinguished between active, callusing, and callused cankers. Active cankers showed a red, actively growing border and were often sunken in appearance, exposing the wood of the stem. In callusing cankers, callus tissue started to wall off the lesion (Fig. 2). The wood of the stem was still exposed but the canker stopped expanding. In completely callused cankers, the lesions were finally totally walled off with newly formed bark tissue and the wood was no longer exposed. It is important to note that these morphological features of callusing and callused cankers are characteristic for chestnut blight lesions that had been initiated artificially by wounding the tree to the depth of the cambium. In the case of natural infection, inactive cankers are often superficial and characterized by a dry black surface, as described above (Fig. 1). In our assessment, we also recorded dead sprouts and recorded whether or not they had died due to $C$. parasitica infection. A girdling canker that had killed the sprout above the infection site indicated mortality caused by C. parasitica.

To determine the presence or absence of virus infection or to assess the invasion of foreign vc types into the chestnut blight canker, $C$. parasitica reisolations were performed at five different points in time: March and November 1997, September 2000, August 2004, and September 2008. At each time, three bark samples per canker were taken with a cork borer $(5 \mathrm{~mm}$ in diameter) (i.e., one at the top, one in the middle, and one at the bottom of the canker). The cork borer was flame sterilized with
$70 \%$ ethanol between cankers. Pure cultures of $C$. parasitica were obtained by first isolating the fungus from the surface-sterilized bark samples on water agar followed by culturing on PDA (26). Because culture morphology is an indicator of CHV-1 infection (8), C. parasitica isolates were determined to be virus-infected if they displayed the white culture morphology and to be virus-free if they displayed the orange morphology $(22,28)$. Cankers from which only virus-free isolates were recovered were coded "O" (orange), cankers from which only virus-infected isolates were recovered were coded "W" (white), and cankers from which both virus-infected and virus-free isolates were recovered were coded "M" (mixed). These data were used to calculate the percentage of virus-free, virus-infected, and mixed cankers at each date investigated.

Based on the reisolations in September 2000, August 2004, and September 2008, we also determined whether the isolates recovered were of the same vc type as the original strains used for the sprout inoculations. Therefore, we paired the isolate and the original strain on the same PDA plate as described previously for $\mathrm{vc}$ type testing $(5,11)$. If barrage formation was observed between the two colonies, the two isolates were regarded as vegetatively incompatible (i.e., of different vc type). If the two colonies merged without barrage formation, they were considered to be vegetatively compatible (i.e., sharing the same vc type). Cankers from which only vegetatively compatible isolates were recovered were coded "C" (compatible), cankers from which only vegetatively incompatible isolates were recovered were coded "I" (incompatible), and cankers from which both vegetatively compatible and incompatible isolates were recovered were coded "M" (mixed). The recovery of an isolate that was incompatible with the original strain indicated an immigration of a new fungal strain into the canker.

Data analysis. At each assessment date in both inoculation experiments, we calculated the mean canker area from the five replicates of each $C$. parasitica strain. The shape of the lesions

TABLE 1. Cryphonectria parasitica strains used for inoculation experiments

\begin{tabular}{|c|c|c|c|c|c|c|c|}
\hline \multirow[b]{2}{*}{ Name } & \multirow[b]{2}{*}{ Type $^{t}$} & \multirow[b]{2}{*}{$\mathrm{CHV}-1^{\mathrm{u}}$} & \multirow[b]{2}{*}{ Vc type ${ }^{\mathrm{V}}$} & \multicolumn{2}{|c|}{ Isolation $^{w}$} & \multicolumn{2}{|c|}{ Application $^{\mathrm{x}}$} \\
\hline & & & & Location & Year & Seedling experiment & Sprout experiment \\
\hline $51 \mathrm{~A}$ & O-active & No & EU-2 & Lumino & 1994 & Yes & Yes \\
\hline $76 \mathrm{~B}$ & O-active & No & EU-5 & Lumino & 1994 & Yes & Yes \\
\hline $303 \mathrm{~A}$ & O-active & No & EU-6 & Gnosca & 1994 & Yes & Yes \\
\hline $335 \mathrm{~B}$ & O-active & No & EU-2 & Gnosca & 1994 & Yes & No \\
\hline $357 \mathrm{~A}$ & O-active & No & EU-5 & Gnosca & 1994 & Yes & No \\
\hline $17 \mathrm{~A}$ & O-inactive & No & EU-1 & Lumino & 1994 & Yes & No \\
\hline $314 \mathrm{~A}$ & O-inactive & No & EU-2 & Gnosca & 1994 & Yes & Yes \\
\hline $323 \mathrm{~A}$ & O-inactive & No & EU-1 & Gnosca & 1994 & Yes & Yes \\
\hline $332 \mathrm{~A}$ & O-inactive & No & EU-1 & Gnosca & 1994 & Yes & No \\
\hline $356 \mathrm{~A}$ & O-inactive & No & EU-5 & Gnosca & 1994 & Yes & Yes \\
\hline $20 \mathrm{~A}$ & $\mathrm{~W}$-active & Yes & EU-21 & Lumino & 1994 & Yes & No \\
\hline $25 \mathrm{~A}$ & $\mathrm{~W}$-active & Yes & EU-5 & Lumino & 1994 & Yes & No \\
\hline $40 \mathrm{~A}$ & $\mathrm{~W}$-active & Yes & EU-5 & Lumino & 1994 & Yes & No \\
\hline $344 \mathrm{~A}$ & $\mathrm{~W}$-active & Yes & EU-9 & Gnosca & 1994 & Yes & No \\
\hline $338 \mathrm{~A}$ & $\mathrm{~W}$-active & Yes & EU-15 & Gnosca & 1994 & Yes & No \\
\hline $29 \mathrm{~A}$ & $\mathrm{~W}$-inactive & Yes & EU-2 & Lumino & 1994 & Yes & No \\
\hline $43 \mathrm{~A}$ & $\mathrm{~W}$-inactive & Yes & EU-5 & Lumino & 1994 & Yes & No \\
\hline $44 \mathrm{~A}$ & $\mathrm{~W}$-inactive & Yes & EU-5 & Lumino & 1994 & Yes & No \\
\hline $63 \mathrm{~A}$ & $\mathrm{~W}$-inactive & Yes & EU-2 & Lumino & 1994 & Yes & No \\
\hline $310 \mathrm{~A}$ & $\mathrm{~W}$-inactive & Yes & EU-2 & Gnosca & 1994 & Yes & No \\
\hline M1115y & O-control & No & EU-2 & Gorduno & 1976 & Yes & Yes \\
\hline M1095 & W-control & Yes & EU-2 & n.a. & n.a. & Yes & Yes \\
\hline
\end{tabular}

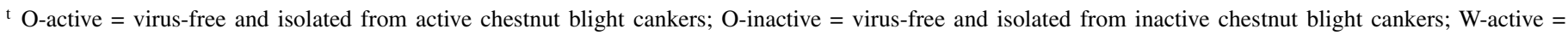
virus-infected and isolated from active chestnut blight cankers; $\mathrm{W}$-inactive $=$ virus-infected and isolated from inactive chestnut blight cankers. The letter $\mathrm{O}$ refers to the orange culture morphology of virus-free strains and the letter W refers to the white culture morphology of virus-infected strains.

u Cryphonectria hypovirus 1 .

v Vegetative compatibility type (11).

${ }^{w}$ All strains were obtained from southern Switzerland; n.a. = not applicable because strain was created in the laboratory.

${ }^{x}$ Application in this study.

y The virus-free strain M1115 was obtained from the fungal culture collection at WSL. It had been stored freeze-dried to avoid subculturing (25).

z The virus-infected strain M1095 is isogenic with strain M1115 and was created in the laboratory by virus infection of strain M1115 (25). 
resembled an ellipse; thus, we used the mathematical formula for an ellipse to calculate the size of the lesions. In the seedling experiment, we used the analysis of variance (ANOVA) in SPSS 19.0 (SPSS, Somers, NY) with strain type as the only factor to analyze the influence of the strain type (O-active, O-inactive, $\mathrm{W}$-active, or $\mathrm{W}$-inactive) on the canker area at a given time after inoculation. The Tukey's post-hoc test was implemented to detect significant differences $(\alpha<0.05)$ among strain types. Repeatedmeasures ANOVA was conducted with a reduced number of factors (i.e., orange versus white strains and strains from active versus inactive cankers). We also calculated the mean mortality caused by each $C$. parasitica strain and performed ANOVA and Tukey's test as described above. In the sprout inoculation experiment, we used ANOVA with strain type (O-active or Oinactive) as the only factor to detect significant differences $(P<$ $0.05)$ between the strain types on the canker area at the given time after inoculation. We also performed a repeated-measures
ANOVA with the four time points to test for significant difference in canker growth between $\mathrm{O}$-active and $\mathrm{O}$-inactive strain types over time. The residuals of all ANOVAs in both experiments were normally distributed and displayed constant error variances.

\section{RESULTS}

Virulence of $\boldsymbol{C}$. parasitica strains isolated from active and inactive chestnut blight cankers. In the chestnut seedling experiment, no significant differences were observed at all assessment dates between $C$. parasitica strains that had been recovered from active cankers and $C$. parasitica strains that had been recovered from inactive cankers, neither among virus-infected nor among virus-free strains (Table 2). This was true for both canker size and mortality of chestnut seedlings. Repeated-measures ANOVA also indicated that there was no significant difference in canker growth between strains recovered from active versus
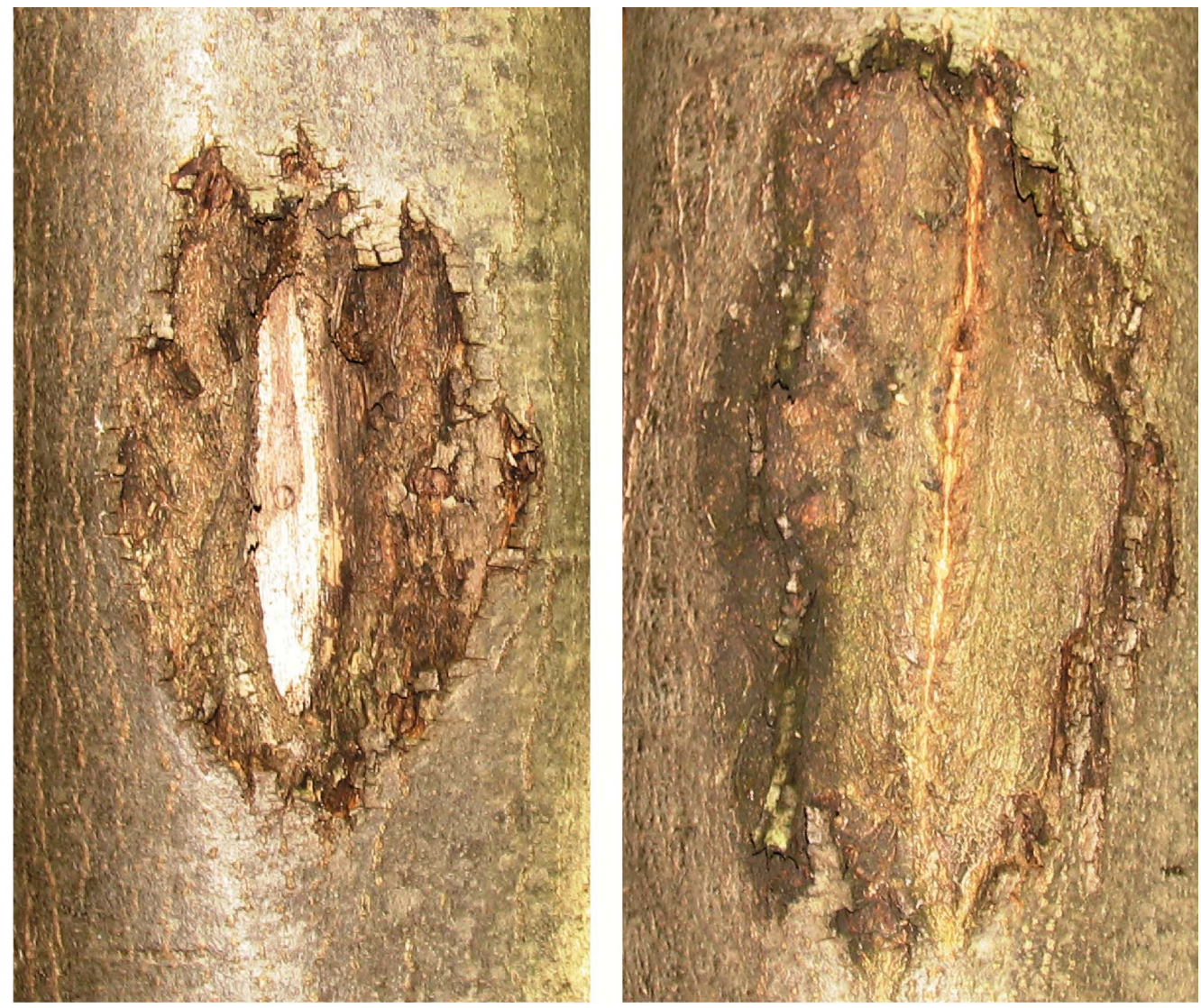

Fig. 2. Callusing (left) and callused (right) chestnut blight cankers after artificial inoculation of Cryphonectria parasitica with a cork borer (see circular wound in the center of the callusing canker on the left). These pictures were taken in 2004, 9 years after inoculations, and the cankers were 16 (left) and $22 \mathrm{~cm}$ (right) long, respectively.

TABLE 2. Chestnut blight canker area on chestnut seedlings and chestnut seedling mortality induced by virus-free and virus-infected Cryphonectria parasitica strains isolated from active and inactive cankers

\begin{tabular}{lccrc}
\hline & & Canker area $\left(\mathrm{cm}^{2}\right)^{\mathrm{y}}$ & \\
\cline { 2 - 4 } Type & \multicolumn{1}{c}{ 2 months } & 6 months & 13 months & Mortality $(\%)^{\mathrm{z}}$ \\
\hline O-active & $35.38 \pm 5.68 \mathrm{a}$ & $65.06 \pm 17.95 \mathrm{a}$ & $146.37 \pm 30.20 \mathrm{a}$ & $53 \pm 18 \mathrm{a}$ \\
O-inactive & $31.42 \pm 7.73 \mathrm{ab}$ & $75.42 \pm 15.94 \mathrm{a}$ & $181.38 \pm 34.98 \mathrm{a}$ & $52 \pm 18 \mathrm{a}$ \\
W-active & $14.21 \pm 8.87 \mathrm{~b}$ & $20.93 \pm 13.94 \mathrm{~b}$ & $30.38 \pm 23.37 \mathrm{~b}$ & $5 \pm 11 \mathrm{~b}$ \\
W-inactive & $28.23 \pm 14.53 \mathrm{ab}$ & $42.44 \pm 23.79 \mathrm{ab}$ & $61.70 \pm 33.99 \mathrm{~b}$ & $8 \pm 18 \mathrm{~b}$ \\
\hline
\end{tabular}

${ }^{\mathrm{x}}$ Four-year-old chestnut seedlings were inoculated on 26 June 1995 with virus-free $(\mathrm{O})$ and virus-infected (W) $C$. parasitica strains isolated from active and inactive chestnut blight cankers.

${ }^{y}$ Mean canker area \pm standard deviation produced by each type at 2, 6, and 13 months after inoculation $(n=5)$. Values within the same column followed by the same letter are not significantly different according to Tukey's test at $\alpha<0.05$.

${ }^{\mathrm{z}}$ Mean percentage of dead chestnut seedlings \pm standard deviation. Values within the same column followed by the same letter are not significantly different according to Tukey's test at $\alpha<0.05$. 
inactive cankers over time (canker type by repeats: $F$ ratio $=1.48$; $P=0.23$ ). However, significant differences in canker size and mortality were observed between virus-infected and virus-free strains (Table 2). The growth of cankers initiated by virus- infected strains was significantly lower than the growth of cankers initiated by virus-free strains (strain-repeats: $F$ ratio $=119.62$, $P<0.0001)$. The differences in size between virus-free and virusinfected cankers increased over the course of time (Table 2). At

TABLE 3. Chestnut blight canker area on chestnut sprouts induced by virus-free and virus-infected Cryphonectria parasitica strains isolated from active and inactive cankers

\begin{tabular}{|c|c|c|c|c|}
\hline \multirow[b]{2}{*}{ Type $^{\mathrm{x}}$} & \multicolumn{4}{|c|}{ Canker area $\left(\mathrm{cm}^{2}\right)^{\mathrm{y}}$} \\
\hline & 6 months & 15 months & 30 months & 39 months \\
\hline O-active & $83.79 \pm 13.40 \mathrm{a}$ & $183.05 \pm 78.03 \mathrm{a}$ & $208.59 \pm 93.63 \mathrm{a}$ & $266.93 \pm 140.87 \mathrm{a}$ \\
\hline O-inactive & $67.35 \pm 9.61 \mathrm{a}$ & $191.56 \pm 93.37 \mathrm{a}$ & $342.62 \pm 234.33 \mathrm{a}$ & $426.50 \pm 296.26 \mathrm{a}$ \\
\hline O-control & 79.92 n.a. & 181.53 n.a. & 202.78 n.a. & n.a.n.a. ${ }^{\mathrm{z}}$ \\
\hline W-control & 17.24 n.a. & 22.66 n.a. & 27.80 n.a. & 27.33 n.a. \\
\hline
\end{tabular}

${ }^{x}$ Eleven-year-old chestnut sprouts were inoculated on 26 June 1995 with virus-free $C$. parasitica strains isolated from active and inactive chestnut blight cankers. As controls, a virus-free $(\mathrm{O})$ and a virus-infected $(\mathrm{W})$ strain from the fungal culture collection at WSL were also used for infections.

y The mean canker area \pm standard deviation produced by virus-free $(\mathrm{O})$-active and O-inactive $C$. parasitica strains at $6,15,30$, and 39 months after inoculation are presented $(n=3)$. For the controls, the canker area at each date is also presented. Values within the same column followed by the same letter are not significantly different according to the analysis of variance with $P<0.05$; n.a. $=$ not applicable.

${ }^{z}$ By September 1998, two of the five sprouts infected with the O-control strain had died. Thus, the mean value for canker size in 1998 was not representative anymore and, therefore, is not presented.

TABLE 4. Virus infection of chestnut blight cankers over the course of 13 years

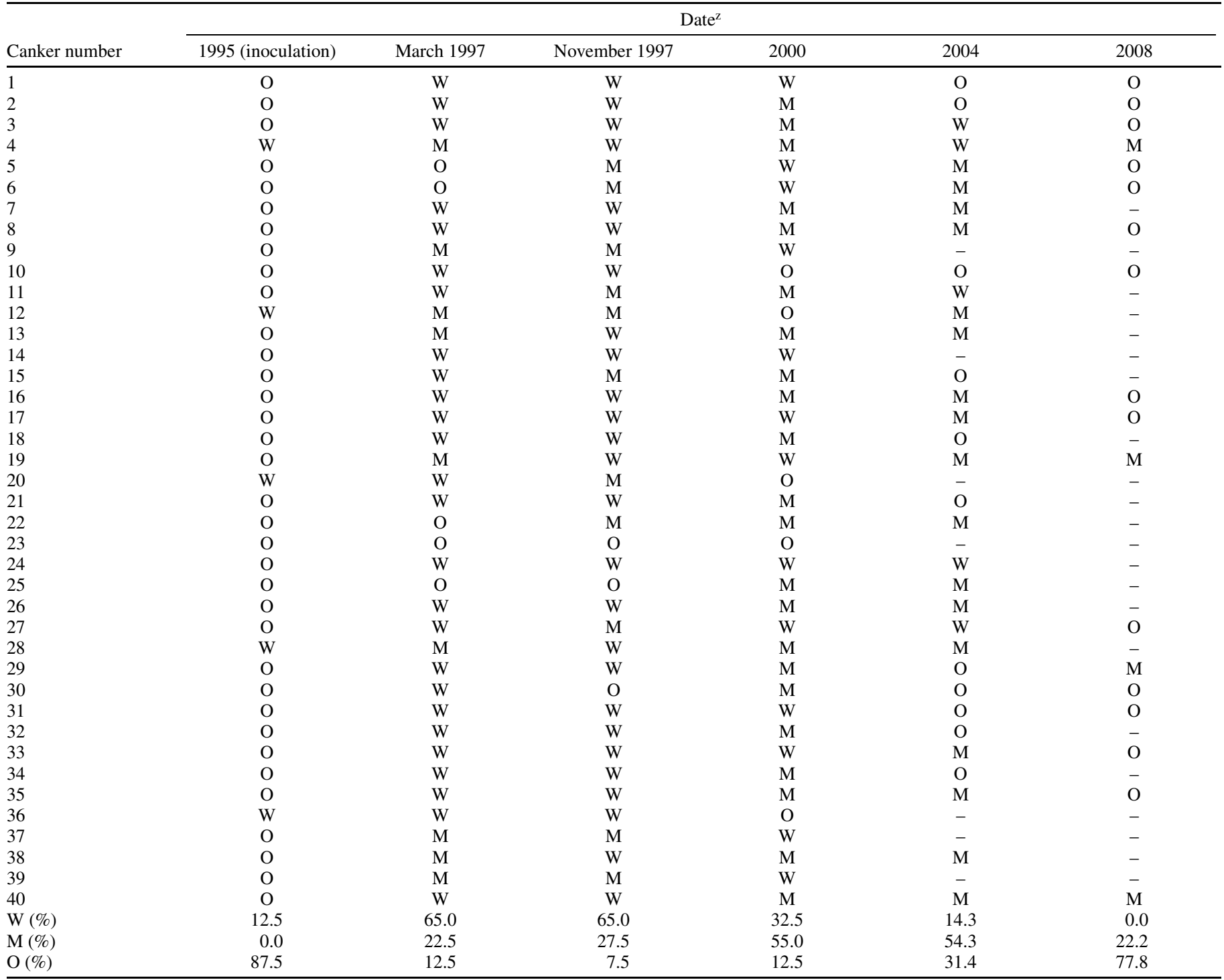

${ }^{\mathrm{z}}$ Thirty-five 11-year-old Castanea sativa sprouts were inoculated with virus-free Cryphonectria parasitica strains and five sprouts were inoculated with virusinfected strains in June 1995. During the course of 13 years, virus infection of the formed chestnut blight cankers was determined at five points in time. At each time, three isolations (top, middle, and bottom of the canker) were made. If all isolates were virus free (i.e., orange), the canker was assigned the code "O", if all isolates were virus-infected (i.e., white), the canker was assigned the code "W", and if both virus-infected and virus-free isolates were obtained from the same canker, the canker was assigned the code "M" (i.e., mixed); - indicates dead sprouts or cankers from which isolations of $C$. parasitica were not successful. At the bottom of the table, the percent values of $\mathrm{O}, \mathrm{W}$, and $\mathrm{M}$ cankers at each point in time are presented. 
the final assessment date, 13 months after inoculation, the mean canker area produced by the virus-infected strains was 2.3- to 6.0fold smaller than the canker area produced by the virus-free strains. Similarly, the mortality of seedlings infected with virusinfected strains was $<10 \%$, whereas the mortality of seedlings infected with virus-free strains was $>50 \%$ (Table 2). The two control strains behaved as expected. The O-control strain produced large cankers and high mortality and the W-control strain small cankers and no mortality (data not shown).

The same pattern was also observed in the chestnut sprout inoculation experiment. No significant differences in canker size (Table 3 ) and canker growth over time (strain-repeats: $F$ ratio $=$ $1.90, P=0.14$ ) were observed between $C$. parasitica strains that had been recovered from active versus inactive cankers at all dates investigated. As on the chestnut seedlings, the main differences in canker size were observed between the virus-free strains and the virus-infected control. These differences also increased over the course of time (Table 3 ).

Dynamics of virus infection and invasion of foreign vegetative compatibility types. Thirty-five cankers had been initiated by virus-free $C$. parasitica strains on chestnut sprouts. From all these cankers, virus-infected strains were isolated at least once between inoculation in 1995 and the end of the observation period in 2008 (Table 4). From the five initially virus-infected cankers, virus-free strains were also isolated at later time points. Virus presence in cankers was very dynamic and the proportions of virus-infected, virus-free, and mixed cankers differed over the course of 13 years. At the beginning, most cankers $(87.5 \%)$ were initiated by virus-free strains. Two years after inoculation all strains recovered from the majority of cankers $(65.0 \%)$ were virus infected. At 5 to 9 years after inoculation the majority of cankers (51.5 to $55.0 \%)$ were mixed (i.e., both virus-infected and virusfree strains were recovered). Finally, 13 years after infection, all cankers on surviving sprouts were inactive cankers (as described below) but, from most cankers $(77.8 \%)$, only virus-free strains were recovered (Table 4). Of the 40 sprouts observed in this study, 12 died over time: six due to $C$. parasitica infection and nine due to other reasons (mostly competition among sprouts within the same cluster).

The number of cankers from which only the original vc type was isolated decreased over time (Table 5). Thirteen years after infection, less than half of all cankers $(33.3 \%)$ only harbored the original vc type. Accordingly, the proportion of cankers harboring foreign vc types increased and reached $66.7 \%$ after 13 years.

Morphological development of chestnut blight cankers. Two years after inoculation, only $26 \%$ of the cankers on living sprouts were active, $61 \%$ were callusing, and $13 \%$ were callused (Fig. 3 ). Over time, the number of active cankers decreased gradually. In 2004 and 2008 (i.e., 9 and 13 years after inoculation), no active cankers were observed anymore. In 1999, the number of callusing cankers also started to decrease. This was associated with an increase in the number of callused cankers (Fig. 3). At the end of the assessment period in 2008, all cankers on surviving sprouts were fully callused, except for two cankers that were still callusing.

\section{DISCUSSION}

In this study, we tested the hypothesis that virus-free $C$. parasitica strains isolated from inactive chestnut blight cankers are less virulent than virus-free $C$. parasitica strains isolated from active cankers. However, we found that these strains did not significantly differ in virulence as assessed by canker growth and host mortality in inoculation experiments. The only difference in virulence was observed between virus-infected and virus-free strains, regardless of whether they were obtained from active or inactive cankers.

C. parasitica strains isolated from active cankers did not produce larger lesions than strains isolated from inactive cankers.
Likewise, these strains did not lead to a higher mortality rate of chestnut seedlings. Significant differences in virulence were observed between virus-infected and virus-free strains, as expected. Virus-infected strains produced significantly smaller lesions than virus-free strains on chestnut seedlings and sprouts. These differences in lesion size became more accentuated over time. In addition, virus-infected strains caused significantly lower, nearly marginal mortality rates in chestnut seedlings. It is unlikely that differences in susceptibility or resistance among chestnut trees

TABLE 5. Presence of different vegetative compatibility types of Cryphonectria parasitica in chestnut blight cankers over the course of 13 years

\begin{tabular}{|c|c|c|c|c|}
\hline \multirow[b]{2}{*}{ Canker number } & \multicolumn{4}{|c|}{ Date $^{y}$} \\
\hline & $1995^{z}$ & 2000 & 2004 & 2008 \\
\hline 1 & EU-2 & $\mathrm{C}$ & M & I \\
\hline 2 & EU-5 & M & $\mathrm{I}$ & I \\
\hline 3 & EU-6 & M & $\mathrm{C}$ & $\mathrm{C}$ \\
\hline 4 & EU-2 & $\mathrm{C}$ & $\mathrm{C}$ & M \\
\hline 5 & EU-2 & $\mathrm{C}$ & M & I \\
\hline 6 & EU-1 & I & I & M \\
\hline 7 & EU-2 & I & I & - \\
\hline 8 & EU-5 & M & M & $\mathrm{M}$ \\
\hline 9 & EU-2 & $\mathrm{C}$ & - & - \\
\hline 10 & EU-5 & $\mathrm{C}$ & I & M \\
\hline 11 & EU-6 & M & $\mathrm{C}$ & - \\
\hline 12 & EU-2 & $\mathrm{C}$ & M & - \\
\hline 13 & EU-2 & M & M & - \\
\hline 14 & EU-1 & $\mathrm{C}$ & - & - \\
\hline 15 & EU-2 & M & M & - \\
\hline 16 & EU-5 & M & $\mathrm{C}$ & $\mathrm{M}$ \\
\hline 17 & EU-2 & $\mathrm{C}$ & $\mathrm{C}$ & $\mathrm{C}$ \\
\hline 18 & EU-5 & $\mathrm{C}$ & I & - \\
\hline 19 & EU-6 & M & $\mathrm{C}$ & $\mathrm{M}$ \\
\hline 20 & EU-2 & $\mathrm{C}$ & - & - \\
\hline 21 & EU-2 & $\mathrm{C}$ & $\mathrm{C}$ & - \\
\hline 22 & EU-1 & $\mathrm{C}$ & $\mathrm{C}$ & - \\
\hline 23 & EU-2 & $\mathrm{C}$ & - & - \\
\hline 24 & EU-5 & $\mathrm{C}$ & $\mathrm{C}$ & - \\
\hline 25 & EU-2 & $\mathrm{C}$ & $\mathrm{C}$ & - \\
\hline 26 & EU-5 & M & I & - \\
\hline 27 & EU-6 & $\mathrm{C}$ & $\mathrm{C}$ & I \\
\hline 28 & EU-2 & $\mathrm{C}$ & M & - \\
\hline 29 & EU-2 & M & M & $\mathrm{C}$ \\
\hline 30 & EU-1 & $\mathrm{C}$ & M & I \\
\hline 31 & EU-2 & $\mathrm{C}$ & $\mathrm{C}$ & $\mathrm{C}$ \\
\hline 32 & EU-5 & $\mathrm{C}$ & $\mathrm{C}$ & - \\
\hline 33 & EU-2 & $\mathrm{C}$ & nd & $\mathrm{C}$ \\
\hline 34 & EU-5 & $\mathrm{C}$ & $\mathrm{C}$ & - \\
\hline 35 & EU-6 & $\mathrm{C}$ & $\mathrm{C}$ & $\mathrm{M}$ \\
\hline 36 & EU-2 & $\mathrm{C}$ & - & - \\
\hline 37 & EU-2 & $\mathrm{C}$ & - & - \\
\hline 38 & EU-1 & $\mathrm{C}$ & $\mathrm{C}$ & - \\
\hline 39 & EU-2 & $\mathrm{C}$ & - & - \\
\hline 40 & EU-5 & $\mathrm{C}$ & $\mathrm{C}$ & $\mathrm{C}$ \\
\hline I $(\%)$ & n.a. & 5.0 & 18.8 & 27.8 \\
\hline $\mathrm{M}(\%)$ & n.a. & 25.0 & 28.1 & 38.9 \\
\hline $\mathrm{C}(\%)$ & n.a. & 70.0 & 53.1 & 33.3 \\
\hline
\end{tabular}

y Forty 11-year-old Castanea sativa sprouts were infected with Cryphonectria parasitica strains of different vegetative compatibility (vc) type (EU-1, EU-2, EU-5, or EU-6) in June 1995. During the course of 13 years, the presence of different vc types in formed chestnut blight cankers was determined at three points in time. At each time, three isolations (top, middle, and bottom of the canker) were made. If all isolates were of the same vc type as the original isolate, the canker was assigned the code "C" (i.e., compatible); if all isolates were of a different vc type than the original isolate, the canker was assigned the code "I" (i.e., incompatible); and if isolates of both the same and of different vc types were obtained from the same canker, the canker was assigned the code "M" (i.e., mixed); - indicates dead sprouts or cankers from which isolations of $C$. parasitica were not successful; nd $=$ not determined due to contamination of the isolated fungal culture the vc type. At the bottom of the table, the percent values of $\mathrm{C}$, I, and $\mathrm{M}$ cankers at each point in time are displayed; n.a. = not available.

z Year of inoculation, vc type. 
were responsible for the observed morphology and mortality. In the seedling inoculation experiment, all seedlings were offspring of the same mother tree and, thus, large differences in susceptibility or resistance were not expected. In the sprout inoculation experiment, all sprout clusters were situated in the same forest stand. It had been shown previously that little variation in susceptibility or resistance was present within the chestnut populations in the area where the experiment was conducted (4). Therefore, differences in morphology and mortality can mainly be attributed to hypovirulence induced by virus infection.

In this and in previous studies $(5,8,23)$, we isolated virus-free strains from inactive cankers. Here, we investigated the dynamics of virus infection in chestnut blight cankers. Therefore, we artificially initiated 35 virus-free and 5 virus-infected cankers in a chestnut stand with naturally occurring hypovirulence and then periodically assessed the presence of CHV-1 in these cankers over the course of 13 years. During the examination period, each of the cankers was virus infected on at least one assessment date. All cankers changed between virus-free and virus-infected states. Similar observations had been made previously for naturally occurring chestnut blight cankers in the same region (5). Within the first 2 years after infection, virus infection increased rapidly and $\mathrm{CHV}-1$ was soon found in the vast majority of cankers. In the following 11 years, however, virus infection decreased gradually to very low numbers. Nevertheless, all cankers on surviving sprouts were inactive (callused or callusing) at the end of the examination period. No active cankers were observed 9 years after inoculation and onwards.

The Cryphonectria-hypovirus pathosystem is a textbook example for a natural biological control system that has been very successful $(1,14)$. In extensively managed ecosystems, such as forests, biocontrol agents should establish in the long term, exerting sufficient control without the need for recurrent human interventions (17,21). Therefore, suitable biocontrol agents are expected to spread independently after initial treatments. The results of this study demonstrate the effectiveness of CHV-1 dissemination within a forest with naturally established hypo- virulence without human help. In our study, all initially virus-free cankers became naturally virus infected within a short time period. Therefore, virus infections of cankers initiated by virusfree $C$. parasitica strains seem to occur rapidly if virus-infected inoculum is present in the population.

Our results suggest that callusing of cankers and cessation of canker expansion is directly attributed to virus infection. However, CHV-1 seems to not persist in these inactive cankers and, thus, to disappear over time. A potential explanation for this lack of persistence of $\mathrm{CHV}-1$ in inactive cankers may be found in the histopathology of virus-infected cankers. Callusing of virusinfected cankers is associated with cessation of canker expansion (13) and, finally, inhibits the growth of $C$. parasitica completely. The containment and inactivation of $C$. parasitica in these cankers could lead to the disappearance of $\mathrm{CHV}-1$ from the fungal mycelium. CHV-1 is an obligate parasite and completely dependent on the metabolism of its fungal host (20). Therefore, it requires an active fungal mycelium to maintain a significant virus concentration. This could explain why CHV-1 cannot always be isolated from inactive, previously virus-infected cankers. Such difficulties in isolating CHV-1 from inactive cankers have been experienced before $(8,18,23)$. However, it is important to note that the $C$. parasitica strains contained in inactive cankers do not differ in virulence from $C$. parasitica strains present in active cankers. When isolated and inoculated onto fresh seedlings or sprouts, these virus-free strains are all highly virulent.

This finding may have implications for forest management. It has been reported that $C$. parasitica strains contained in inactive cankers may resume their activity after the tree or sprout had been cut or weakened after fire, drought, or death due to competition (23). C. parasitica from inactive cankers started to grow and sporulate abundantly as a saprophyte on the dying host tissue for at least 1 to 2 years. Foresters and chestnut orchard managers should take this possibility into account when cutting or pruning chestnut sprouts or trees. On the one hand, inactive cankers on recently cut sprouts or stems may serve as a source of hypovirulent, virus-infected inoculum if $\mathrm{CHV}-1$ is still present in the

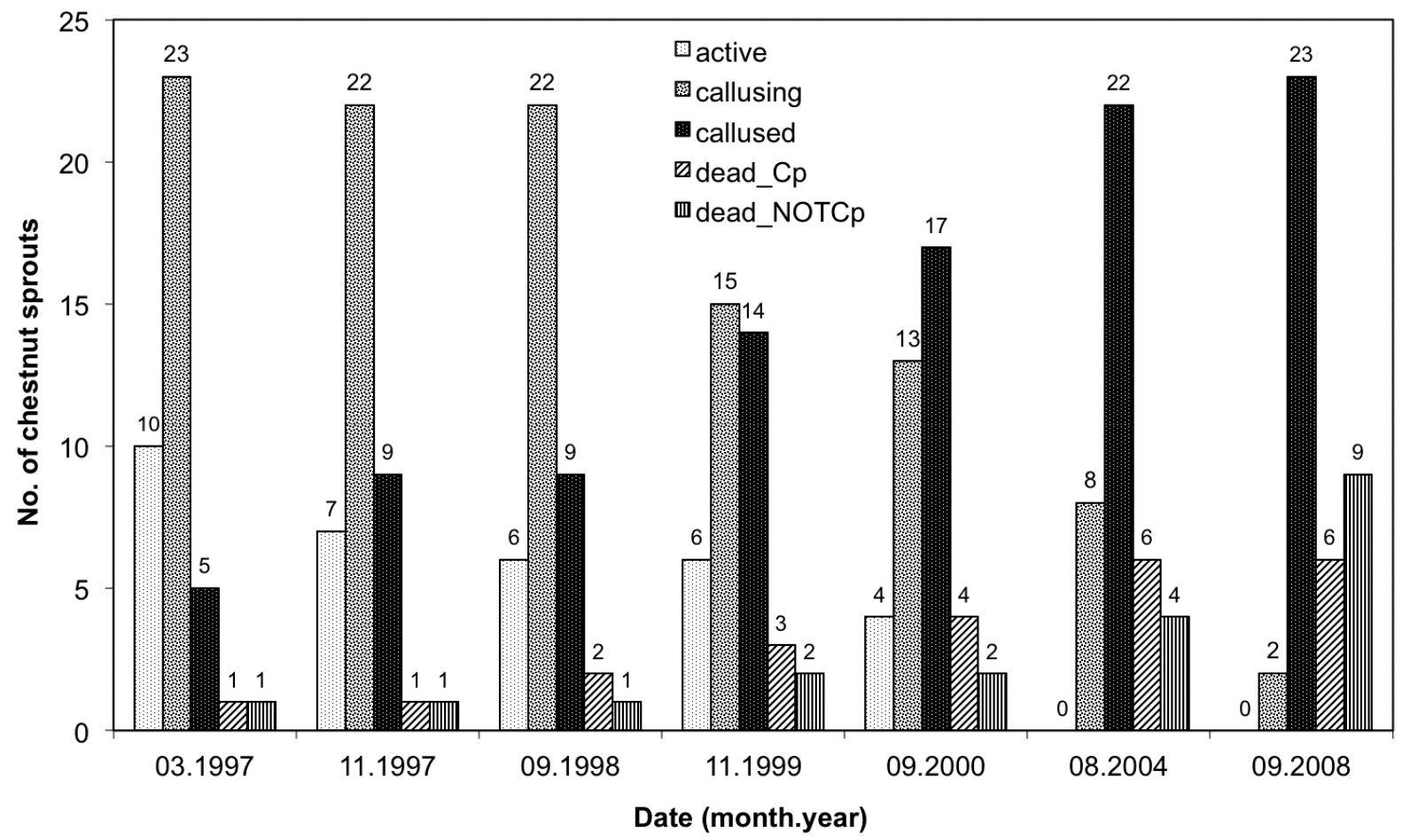

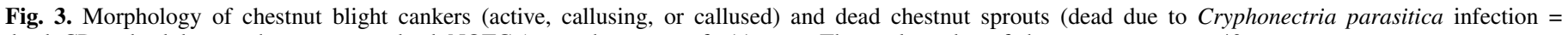
dead_CP or dead due to other reasons $=$ dead_NOTCp) over the course of $\approx 11$ years. The total number of chestnut sprouts was 40 . 
fungal mycelium (23). This would be favorable for the biological control of chestnut blight because it would promote the natural dissemination of CHV-1. On the other hand, in cases where CHV-1 had disappeared from the fungal mycelium over time, the opposite effect would be observed. Inactive cankers on recently cut chestnut wood could become a source of virulent, virus-free chestnut blight inoculum. This could eventually lead to an increase in both disease incidence and severity. The importance of such virulent sporulation on cut or weakened sprouts or trees for the sustainability of the biocontrol system should be further investigated. Our results indicate that the chances of disappearance of CHV-1 from inactive cankers increased with increasing age of the canker. As a forest health management practice, therefore, the removal of the cut sprouts or trees from the site should be well considered if they are associated with inactive cankers.

The dynamic nature of the Cryphonectria-hypovirus pathosystem is illustrated not only by the variability in virus infection described above but also by the immigration of foreign vc types into chestnut blight cankers. In our study, the percentage of cankers from which vc types incompatible with the original vc type were recovered increased over time and affected the majority of cankers 13 years after inoculation. This shows that not only the virus presence but also the fungal strain composition changes over time in a canker. Chestnut blight cankers seem to be an open system, serving as both a source and sink for fungal and viral inoculum. Invasion of existing cankers by either virus-free or virus-infected fungal individuals and transmission of $\mathrm{CHV}-1$ among these individuals results in a dynamic fungus-virus system. Therefore, we suggest that studies not focus on virus infection and $C$. parasitica strain composition within individual cankers. Instead, incidence of virus infection and fungal strain composition within a population or forest should be used to assess the overall disease severity. Under the presence of a sufficient virus incidence within the population, a low disease severity will most likely be maintained over time.

In conclusion, our study showed that the Cryphonectriahypovirus pathosystem is a very dynamic but effective biocontrol system. Virus infection and fungal strain composition of chestnut blight cankers change over time. Under the presence of natural hypovirulence in the area, virus-free cankers become virusinfected within a few years, leading to inactive cankers. In these cankers, the virus might not persist over time. Therefore, inactive cankers can also harbor virus-free strains of $C$. parasitica. The virulence of these virus-free strains is not naturally low when inoculated onto living seedlings or sprouts. They are as virulent as virus-free strains isolated from active cankers. These findings are important for forest health management. On the one hand, CHV-1 seems to disseminate efficiently within a population, leading to hypovirulence and healing of cankers. On the other hand, old, inactive cankers may serve as a source of virulent, virus-free chestnut blight inoculum due to the saprophytic activity of C. parasitica in freshly cut trees. These factors should be considered in forest management practices as well as in biological control programs.

\section{ACKNOWLEDGMENTS}

We thank U. Heiniger for help with the assessments of canker growth and with the fungal reisolations in the field and H. Blauenstein for assistance with the laboratory work.

\section{LITERATURE CITED}

1. Anagnostakis, S. L. 1982. Biological control of chestnut blight. Science 215:466-471.

2. Anagnostakis, S. L. 1987. Chestnut blight-the classical problem of an introduced pathogen. Mycologia 79:23-37.

3. Anagnostakis, S. L. 1988. Cryphonectria parasitica, cause of chestnut blight. Adv. Plant. Pathol. 6:123-136.

4. Bazzigher, G. 1981. Selection of blight-resistant chestnut trees in Switzerland. Eur. J. For. Pathol. 11:199-207.

5. Bissegger, M., Rigling, D., and Heiniger, U. 1997. Population structure and disease development of Cryphonectria parasitica in European chestnut forests in the presence of natural hypovirulence. Phytopathology 87:50-59.

6. Bryner, S. F., and Rigling, D. 2012. Hypovirus virulence and vegetative incompatibility in populations of the chestnut blight fungus. Phytopathology 102:1161-1167.

7. Bryner, S. F., Rigling, D., and Brunner, P. C. 2012. Invasion history and demographic pattern of Cryphonectria hypovirus 1 across European populations of the chestnut blight fungus. Ecol. Evol. 2:3227-3241.

8. Bryner, S. F., Sotirovski, K., Akilli, S., Risteski, M., Perlerou, C., and Rigling, D. 2013. Informative value of canker morphology on the presence or absence of virus infection in chestnut blight cankers. For. Pathol. 43:496-504.

9. Choi, G. H., and Nuss, D. L. 1992. Hypovirulence of chestnut blight fungus conferred by an infectious viral cDNA. Science 257:800-803.

10. Cortesi, P., and Milgroom, M. G. 1998. Genetics of vegetative incompatibility in Cryphonectria parasitica. Appl. Environ. Microbiol. 64:29882994.

11. Cortesi, P., Rigling, D., and Heiniger, U. 1998. Comparison of vegetative compatibility types in Italian and Swiss subpopulations of Cryphonectria parasitica. Eur. J. For. Pathol. 28:167-176.

12. Dutech, C., Barres, B., Bridier, J., Robin, C., Milgroom, M. G., and Ravigne, V. 2012. The chestnut blight fungus world tour: successive introduction events from diverse origins in an invasive plant fungal pathogen. Mol. Ecol. 21:3931-3946.

13. Hebard, F. V., Griffin, G. J., and Elkins, J. R. 1984. Developmental histopathology of cankers incited by hypovirulent and virulent isolates of Endothia parasitica on susceptible and resistant chestnut trees. Phytopathology 74:140-149.

14. Heiniger, U., and Rigling, D. 1994. Biological control of chestnut blight in Europe. Annu. Rev. Phytopathol. 32:581-599.

15. Heiniger, U., and Rigling, D. 2009. Application of the Cryphonectria Hypovirus (CHV-1) to control the chestnut blight, experience from Switzerland. Acta Hortic. 815:233-245.

16. Hillman, B. I., and Suzuki, N. 2004. Viruses of the chestnut blight fungus, Cryphonectria parasitica. Adv. Virus Res.:423-472.

17. Hufbauer, R. A., and Roderick, G. K. 2005. Microevolution in biological control: mechanisms, patterns, and processes. Biol. Control 35:227-239.

18. McManus, P. S., Ewers, F. W., and Fulbright, D. W. 1989. Characterization of the chestnut blight canker and the localization and isolation of the pathogen Cryphonectria parasitica. Can. J. Bot. 67:3600-3607.

19. Milgroom, M. G., and Cortesi, P. 2004. Biological control of chestnut blight with hypovirulence: a critical analysis. Annu. Rev. Phytopathol. 42:311-338.

20. Nuss, D. L. 2005. Hypovirulence: mycoviruses at the fungal-plant interface. Nat. Rev. Microbiol. 3:632-642.

21. Payne, C. C. 1988. Pathogens for the control of insects: where next? Philos. Trans. R. Soc. Lond. B Biol. Sci. 318:225-248.

22. Peever, T. L., Liu, Y. C., Cortesi, P., and Milgroom, M. G. 2000. Variation in tolerance and virulence in the chestnut blight fungus-hypovirus interaction. Appl. Environ. Microbiol. 66:4863-4869.

23. Prospero, S., Conedera, M., Heiniger, U., and Rigling, D. 2006. Saprophytic activity and sporulation of Cryphonectria parasitica on dead chestnut wood in forests with naturally established hypovirulence. Phytopathology 96:1337-1344.

24. Prospero, S., and Rigling, D. 2013. Chestnut blight. In: Infectious Forest Diseases. P. Gonthier and G. Nicolotti, eds. CAB International, Wallingford, UK.

25. Rigling, D. 1995. Isolation and characterization of Cryphonectria parasitica mutants that mimic a specific effect of hypovirulence-associated dsRNA on laccase activity. Can. J. Bot. 73:1655-1661.

26. Roane, M. K., Griffin, G. J., and Elkins, J. R. 1986. Chestnut blight, other Endothia diseases, and the genus Endothia. In: APS Monograph Series. American Phytopathological Society, St. Paul, MN.

27. Robin, C., and Heiniger, U. 2001. Chestnut blight in Europe: diversity of Cryphonectria parasitica, hypovirulence and biocontrol. For. Snow Landsc. Res. 76:361-367.

28. Robin, C., Lanz, S., Soutrenon, A., and Rigling, D. 2010. Dominance of natural over released biological control agents of the chestnut blight fungus Cryphonectria parasitica in south-eastern France is associated with fitness-related traits. Biol. Control 53:55-61.

29. Van Alfen, N. K., Jaynes, R. A., Anagnostakis, S. L., and Day, P. R. 1975. Chestnut blight-biological control by transmissible hypovirulence in Endothia parasitica. Science 189:890-891. 